\title{
El "alma de la colonia". La significación histórica de la prensa inmigrante portuguesa en los Estados Unidos: cultura, lengua y periodismo
}

Alberto Pena Rodríguez

Universidad de Vigo (España)

María Ėrica de Oliveira Lima

Universidad Federal de Ceará (Brasil) 



\title{
El "alma de la colonia". La significación histórica de la prensa inmigrante portuguesa en los Estados Unidos: cultura, lengua y periodismo
}

\section{The "Soul of the Colony". The historical significance of the Portuguese Ethnic Press in the United States: culture, language and communication}

\author{
Alberto Pena Rodríguez \\ Universidad de Vigo (España) \\ penarodriguezalberto@gmail.com \\ María Èrica de Oliveira Lima \\ Universidad Federal de Ceará (Brasil) \\ merical@uol.com.br
}

Fecha de recepción: 26 de octubre de 2018

Fecha de aceptación: 31 de mayo de 2020

\section{Resumen}

El objetivo fundamental de este trabajo es aproximarse a la significación histórica de la prensa inmigrante portuguesa en los Estados Unidos de América, prestando especial atención a aquellos elementos de carácter narrativo que han contribuído a crear un discurso simbólico y a dar un sentido trascendente y etnocéntrico a la presencia portuguesa en Norteamérica. Mediante una aproximación cuantitativa y cualitativa que emplea técnicas de análisis del discurso, el artículo intenta ofrecer una radiografía general sobre los aspectos más paradigmáticos de la narrrativa periodística de este tipo de prensa relacionados con el imaginario cultural lusófono en Estados Unidos.

Palabras clave: Inmigración portuguesa; Prensa étnica; Estados Unidos; Periodismo; Lengua

\footnotetext{
Abstract

The main objective of this work is to approach the historical significance of the Portuguese immigrant press in the United States of America, paying special attention to those elements of a narrative nature that have contributed to create
} 
El "alma de la colonia"... - A. Pena Rodríguez y M. È. de Oliveira Lima

a symbolic discourse and to give a transcendental and ethnocentric meaning to the Portuguese presence in North America. Through a quantitative and qualitative approach that uses techniques of discourse analysis, the article intends to offer a general radiography on the most paradigmatic aspects of the journalistic narrative of this type of press related to the Portuguese-American cultural imaginary in the United States.

Keywords: Portuguese Immigration; Ethnic Press; United States; Journalism; Language.

\section{INTRODUCGIÓN}

Este trabajo es una aproximación a la historia de la prensa étnica portuguesa en Estados Unidos, prestando especial atención al estudio de algunas de las representaciones simbólicas más paradigmáticas de su narrativa, que han ayudado a configurar a lo largo del tiempo unas marcas perdurables en el imaginario cultural de los inmigrantes de origen lusófono, basado en elementos históricos y linguísticos que se reflejan en la narrativa de los periódicos difundidos en los diferentes núcleos de la diáspora norteamericana. ${ }^{1}$ Mediante un análisis crítico del discurso centrado en la estructura narrativa, se intenta comprender la evolución de las dinámicas sociocomunicativas desarrolladas por los inmigrantes portugueses en Estados Unidos, mayoritariamente procedentes de los archipiélagos de Azores y Madeira, con unas marcas identitarias que definen su peculiar percepción de la realidad en el marco de una serie de intersecciones culturales situadas en el universo luso-americano.

Tras una oportuna contextualización sobre la emigración portuguesa y la relevancia del fenómeno de la prensa étnica en Norteamérica, el objeto de estudio se centra en explicar cuáles fueron históricamente las principales causas y consecuencias de la producción periodística de los inmigrantes portugueses en Estados Unidos y analizar aquellas marcas narrativas de tipo etnocéntrico que pudieron tener alguna influencia en el desarrollo cultural de la comunidad lusoamericana. Este es un tema novedoso que puede aportar datos de interés para el conocimiento de la historia lusófona en Norteamérica y, particularmente, para aproximarse a la función comunicativa del periodismo luso en la construcción de un imaginario propio. Las referencias téoricas sobre este tema son todavía muy escasas. Los principales trabajos fueron publicados por Leo Pap (1987) y Geoffrey Gomes (1995), cuyas investigaciones no abordan el estudio de la estructura narrativa de este tipo de producción periodística ni aportan información relevante sobre su significación como medios de información.

1 Este trabajo está financiado por la FCT (Fundação para a Ciência e a Tecnologia de Portugal), I.P., en el marco del proyecto de investigación PTDC/COM-JOR/28144/2017 - Para uma história do jornalismo em Portugal. 
La metodología que se emplea en este abordaje es de tipo cualitativo, dentro de un marco general de estudio que se sitúa en la historia del periodismo inmigrante. Se aplican técnicas de observación y análisis crítico del discurso en varios periódicos editados por la comunidad lusófona, principalmente las cabeceras de referencia en la costa Este y Oeste: el Diario de Noticias (New Bedford, Mass.) y el Jornal Português (Oakland, Cal.), respectivamente. El trabajo dispone de tres niveles esenciales de análisis. En primer lugar, se emplea una dimensión diacrónica y sincrónica para conocer panorámicamente el proceso evolutivo del fenómeno. En segundo lugar, se realiza una aproximación temática sobre cuestiones que han tenido un impacto simbólico significativo en la prensa inmigrante portuguesa desde una perspectiva histórica. Y en tercer lugar, se mencionan algunos de los aspectos más característicos de estos medios de comunicación como agentes de dinamización cultural y de creación de una esfera pública específica en la que se enmarca y se legitima su presencia en Estados Unidos. El objetivo fundamental es identificar, describir y analizar los elementos discursivos de tipo simbólico que ayuden a definir algunas marcas simbólicas del imaginario que proyectan los inmigrantes lusos a través de la producción y difusión de sus propios medios informativos, escritos en lengua portuguesa como rasgo esencial de su significación cultural en Estados Unidos.

\section{LA EMIGRAGIÓN PORTUGUESA HAGIA ESTADOS UNIDOS. CONTEXTUALIZAGIÓN HISTÓRICA}

De acuerdo con las investigaciones de Leo Pap (1981), las primeras colonias lusas en territorio norteamericano se remontan a 1640, cuando algunos grupos de judíos de origen portugués se establecen en New Amsterdan (actual New York). Posteriormente, los contactos entre la industria ballenera americana y portuguesa propiciaron la llegada de un número cada vez mayor de azorianos a mediados del siglo XIX, tal y como cuentan Donald Warrin (2010), y David Bertão (2006). Este flujo de emigrantes, atraídos sobre todo por el desarrollo de la industria textil de New Bedford, Fall River y otras ciudades al sur del Estado de Massachusetts, se fue incrementando en décadas posteriores (muchos procedentes también del Portugal continental y Madeira) hasta alcanzar su primer ciclo masivo entre 1880 y 1920 , sobre todo en el período que va de 1900 a 1920, en el que se concentra más de la mitad de la cifra total de inmigrantes entre 1870 y 1930 (Pena et al., 2015; Baganha, 2009; Williams, 2007).

Las causas generales que han provocado este éxodo hay que buscarlas en la falta de recursos económicos, de tierras para cultivar y, especialmente en el caso de Azores, también la superpoblación de las islas (Rocha, 1991; Avendaño, 1982). Las compañías navieras, a se vez, jugaron un papel interesante. Algunas empresas de transporte marítimo trataron de incrementar su negocio haciendo publicidad en la prensa local europea para vender pasajes hacia Estados Unidos (Luca de Tena, 1993). 
Los anuncios prometían toda clase de comodidades y ventajas; algunos incluso anunciaban que era posible llegar hasta la costa Este a través de conexiones ferroviarias con los puertos americanos en los inicios del siglo XX (Williams, 2007, p. 33).

A partir de 1850, algunos emigrantes portugueses comenzaron a llegar a California, con asentamientos en San Francisco y al sur del Estado, donde desarrollaron una intensa actividad agropecuaria. Los colonos lusos crearon plantaciones agrícolas, granjas y pequeños negocios ganaderos que todavía hoy forman parte del tejido económico de los luso-californianos, llegando a controlar cerca de la mitad de la producción lechera de California (Dias, 2009; Graves, 2004; Vaz, 1965). Muchos otros se desarrollaron profesionalmente en la industria de la pesca, trabajando como marineros en barcos que tenían su amarre en varios puntos de la costa californiana y en Nueva Inglaterra, sobre todo en New Bedford, que ha sido históricamente el puerto pesquero de referencia en Massachussets (Zelph, 1889). Entre 1880 y 1900, un importante contingente de portugueses naturales de Azores y Madeira llegaron al archipiélago de Hawai, algunos en barcos balleneros y otros persuadidos por una campaña de reclutamiento entre europeos para trabajar en sus plantaciones de azúcar ((Strone, 1988; Correa \& Knowlton, 1982). El gobierno de Hawai y el de Portugal firmaron el 5 de mayo de 1882 el Provisional Convention Between Portugal and the Hawaiian Islands, mediante el cual se establecía oficialmente un marco legal para el intercambio económico y comercial que amparaba y estimulaba la llegada de trabajadores portugueses. ${ }^{2}$ La mayoría de los que llegaron en este período se agruparon en varias zonas, mayoritariamente en la isla principal, Honolulu, donde se establecieron, sobre todo, en Punchbowl y Kaka'ako. Otros grupos también se instalaron en varios lugares de Kauai y Kona. Poco a poco, los portugueses fueron integrándose en la vida local, abriendo granjas y pequeños negocios de carácter comercial a través de los que introdujeron el consumo de la mantequilla en las islas (Felix \& Senecal, 1978). Las duras condiciones de trabajo y la sensación de aislamiento en los campos hawaianos, hicieron que algunos portugueses sintieran la necesidad de fundar periódicos para proteger sus intereses y afirmar su sentimiento de comunidad (Knowlton, 1960).

Las estimaciones realizadas indican que alrededor de 250.000 emigrantes portugueses (la mayoría naturales de Azores) se establecieron en Estados Unidos entre 1870 y 1921 , de los cuales una cuarta parte regresarían a Portugal en algún momento (Avendaño, 1983, p. 159). ${ }^{3}$ En 1920, cuando las autoridades americanas elaboraron

2 El documento se puede leer íntegro a través de la siguiente dirección web: http:// hawaiiankingdom.org/treaty_portugal.shtml. Información sobre este y otros aspectos relacionados ha sido facilitada también por Sonia Pacheco, bibliotecaria de la Ferreira-Mendes Portuguese-American Archives at UMass Dartmouth.

3 En 1921, se implanta un sistema de cuotas que reduce drásticamente la entrada de inmigrantes del Este y del Suroeste de Europa en favor de los del Norte. La entrada de portugueses se reduce a 440 visados por año. La gran depresión de 1929 empeoró las cosas. Pero la recuperación económica experimentada tras la Segunda Guerra mundial no cambió demasiado el panorama. 
el censo sobre el origen étnico de la población en territorio continental, 105.000 ciudadanos extranjeros de raza blanca reconocieron tener el portugués como lengua materna. De acuerdo con las cifras manejadas por Pap, en 1940 la cantidad descendió a 84.000 porque las nuevas políticas migratorias habían reducido sensiblemente la entrada de nuevos inmigrantes. Según los datos de la Embajada de Portugal en Estados Unidos, en 1930 la colonia luso-americana estaba formada por 376.893 personas, de las cuales aproximadamente 150.000 residían en Massachusetts y Rhode Island, 20.000 en Nueva York y alrededores, y 100.000 en California [Arquivo Histórico Diplomático de Lisboa (AHD). Embajada de Portugal en Washington. Caja $n^{\circ} 18$. Oficio enviado por el secretario de la embajada, João de Deus Ramos, al ministro de Negócios Estrangeiros, $n^{\circ}$ 117, processo 9/34, s. f. (1934)]. Actualmente, según las cifras de distintos organismos de análisis demográfico, la comunidad luso-americana rondaría los 1'2 millones de personas, de las cuales más de la mitad residen en Massachusetts y California (Vicente, 1998, p. 61)

\section{LA RELEVANCIA HISTÓRICA DE LA EDICIÓN PERIODÍSTICA DE GARÁCTER ÉTNICO}

La denominada 'prensa étnica' por la comunidad científica americana es un fenómeno asociado a las comunidades inmigrantes en Estados Unidos, entre las que se halla la lusófona (McDonald, 2007; Miller, 1987). Las causas esenciales que impulsaron la creación de publicaciones periódicas a lo largo del tiempo entre las poblaciones de inmigrantes en Estados Unidos fueron, esencialmente, tres: la necesidad de mantener una relación con sus raíces a través de la lectura de noticias e informaciones que alimentaban el vínculo emocional con su tierra; el deseo de afirmar su identidad cultural y su lengua en un entorno nuevo, en el que desconocían las costumbres y el idioma local; y su función como servicio público para informar sobre la vida de la colonia y ayudar a integrar a los inmigrantes en el nuevo mundo. Las consecuencias de su existencia también fueron varias. Este tipo de prensa creó de un verdadero sentimiento de comunidad entre los miembros de cada núcleo de inmigrantes; contribuyóa su dinamización económica y cultural; aumentó su influencia y participación política; impulsó el desarrollo de proyectos comunitarios; y fue un agente importante en su educación, orientación e integración social (Rhodes, 2010).

Para conocer los rasgos específicos que caracterizan el fenómeno periodístico luso-americano y su verdadera dimensión a lo largo de la historia, es necesario observar los datos cuantitativos dentro del contexto de la prensa étnica norteamericana. Las estadísticas que se conocen a través de los estudios de diversos autores aportan una muestra representativa para comprender la evolución de la prensa en lengua no inglesa en los Estados Unidos de América (Ireland, 1990). En torno a 1910, había más de 1300 periódicos en lengua no inglesa (hasta en 30 lenguas diferentes), según el N. W. and Son's Ayer's American Newspaper Annual and Directory, de los cuales más de 500 eran en alemán, más de 100 en italiano, 75 en sueco y otros tantos en 
español. Aunque esta fuente no proporciona información sobre la prensa portuguesa, según los datos de esta investigación consultados en diversos archivos, en 1910 el número de periódicos en portugués ascendía a 12 títulos. En total, sumando todas las publicaciones étnicas, alcanzaban una tirada estimada de 2,6 millones de ejemplares, y cerca de 150 eran diarios (Blanchard, 1998, p. 207).

En general, en la producción de prensa étnica, se pueden distinguir tres grandes fases relacionadas directamente con los ciclos migratorios a Estados Unidos (Rhodes, 2010 , pp. 5-6). La primera gran oleada comienza en el período colonial y llega hasta 1865, durante la cual se establecieron alrededor de 10 millones de inmigrantes procedentes, sobre todo, de Inglaterra, Irlanda, Alemania, Francia, Escandinavia, Países Bajos y China. En este período, se registraron hasta 300 publicaciones en lenguas extranjeras, sobre todo en francés y alemán, según Blanchard (1998, pp. 207209). Entre 1865 y 1890, comienza una nueva fase con un volumen de inmigrantes parecido. El final de la Guerra Civil americana y de las guerras europeas (las invasiones napoleónicas y el conflito entre Prusia y la alianza franco-austríaca-danesa) y el impulso de la revolución industrial, con el inicio de la era ferroviaria, favorecieron particularmente el movimiento de trabajadores. El mito del Oeste, en busca de tierras gratis para cultivar y la fiebre del oro, fue un importante estímulo añadido. También los feligreses de varias congregaciones religiosas, como los menonitas, los baptistas y los cuáqueros alemanes, se decidieron a emigrar a Estados Unidos cuando algunos Estados del Este europeo crearon leyes que favorecían a determinadas confesiones. En la tercera fase, que iría de 1900 a 1930, continúa el aumento constante de la cifra de periódicos creados por las comunidades de inmigrantes hasta que se imponen las restricciones legales migratorias en los años veinte. The Immigration Act de $1921 \mathrm{y}$ 1924, y The National Origins Formula de 1929, reducen el ritmo de crecimiento de la inmigración y, consecuentemente, el número de periódicos realizados por o para los inmigrantes. Cuantitativamente, en 1886 el número de cabeceras en lengua no inglesa era de 796; en 1900, alcanza los 1163; en 1917, 1323; en 1920, 1052; y en 1930, 1037. El período más productivo fue entre 1884 y 1920, en el que se fundaron 3444 periódicos, la mayoría de existencia efímera, que es uno de los rasgos que definen este tipo de prensa. Estadísticamente, como media, por cada 100 periódicos que se fundaban, 93 cerraban (Miller, 1987, p. 13; Rhodes, 2010, pp. 7-11).

A pesar de la fugacidad de la mayoría, algunos títulos alcanzaron posiciones de relevancia e influencia a lo largo de la historia. La prensa étnica no ha sido un fenómeno marginal, con escaso nivel de impacto en la sociedad norteamericana. Hay numerosos casos que ilustran hasta qué punto este tipo de prensa fue un actor relevante en la estrategia política de algunas organizaciones, las relaciones públicas institucionales y la propia estructura social americana en diferentres períodos históricos. Tal y como relata Leara D. Rhodes, entre las evidencias empíricas más interesantes y paradigmáticas, se podrían citar los casos de tres personajes singulares en la historia americana: Abraham Lincoln, Joseph Pulitzer y Carlo Barsotti. Lincoln decidió comprar en 1859 el periódico étnico alemán Illinois Staatsanzeiger, de 
Springfield, para poder hacer una campaña eficaz entre la comunidad alemana en su carrera hacia la Casa Blanca. Pagó por él 400 dólares a Theodore Canisius, que trabajó a su servicio para captar el voto de los alemanes. Tras la elección, Canisius recuperó el periódico y fue nombrado Cónsul de Estados Unidos en Viena (Wittke, 1957).

Joseph Pulitzer fue un inmigrante nacido en Budapest que llegó a Estados Unidos en 1864 para combatir en la Guerra Civil del lado de los unionistas. Cuando finalizó el conflicto trabajó como reportero del diario alemán con sede en St. Louis Westliche Post. Posteriormente, adquiriría en 1874 el periódico de la misma ciudad Saats-Zeuitung y, más tarde, el St. Louis Dispatch, que fusionó con el Post. En 1887, fundó el Evening World en New York City, que se convirtió en portavoz del partido demócrata. Tuvo una competencia feroz con el New York Morning Journal, de William Randolph Hearst, que fue uno de los empresarios periodísticos más influyentes de la historia de Estados Unidos (Nasaw, 2001). ${ }^{4}$ El tipo de periodismo realizado por Joseph Pulitzer era sensacionalista y está considerado uno de los creadores del llamado "periodismo amarillo". A su muerte, dejó parte de su fortuna a la Columbia University School of Journalism, que creó en 1917 los prestigiosos premios de periodismo que llevan su nombre (Rhodes, 2010, p. 43).

Carlo Barsotti fundó en Nueva York el periódico italiano Il Progresso Italo Americano en 1880, que se transformó en el periódico en lengua no inglesa de mayor tirada de la ciudad. Barsotti utilizó su cabecera para promocionar a la comunidad italiana en Nueva York y ganar así influencia pública. Realizó una campaña que pretendía reconocer la contribución de los italianos al progreso de Estados Unidos. Gracias a sus reportajes e informaciones de elogio a la comunidad italo-americana, consiguió que se inaugurasen varios monumentos conmemorativos en diferentes lugares de la ciudad en honor a personajes históricos de Italia, como Giuseppe Garibaldi, Dante Alighieri y Giovanni da Verazzano (Rhodes, 2010: 43-44). Entre otros muchos ejemplos sobre la influencia de la prensa étnica en la vida política americana, también se podría añadir a uno de los líderes de la independencia americana, Benjamin Franklin, que publicó en 1732, en Philadelphia, un periódico dirigido a los inmigrantes alemanes (Blanchard, 1998, p. 208).

En cuanto a los contenidos, hay estudios específicos que demuenstran que los periódicos creados por las comunidades de inmigrantes establecidas en Estados Unidos tienen una serie de temas comunes. Según las conclusiones del trabajo de J. Zubrzycki citado por Rhodes, hay cinco asuntos que suelen repetirse en este tipo de prensa: informaciones sobre el país de acogida, noticias internacionales, crónicas sobre su propia comunidad, reportajes sobre su país de origen y artículos de opinión o de carácter editorial (Zubrzycki, 1958). Sin embargo, aunque existen lógicas

4 William Randolph Hearst llegó a ser propietario de 28 periódicos de circulación nacional, entre ellos Los Angeles Examiner, The Boston American, The Atlanta Georgian, The Chicago Examiner, The Detroit Times, The Seattle Post-Intelligencer, The Washington Times, The Washington Herald y The San Francisco Examiner, además de poseer varias emisoras radiofónicas, revistas y editoriales. 
similitudes, se pueden observar diferencias notables entre todos ellos a partir de una serie de elementos clave. Por un lado, la propia lengua en sí misma es un factor determinante, pues establece una categoría fundamental en la caracterización del estudio de la prensa étnica. Cada lengua somete la interpretación de la realidad a un proceso de abstracción diferente (Whorf, 1956). Por otro lado, la estructura cultural de la comunidad inmigrante influye en el qué y el cómo se narran los hechos sobre lo que se informa. La idiosincrasia de cada sociedad, basada en las tradiciones culturales y la estructura ideológica de su imaginario étnico, influye y condiciona el discurso informativo (Goulart, 2002). En la construcción de la narración periodística influye, además, el tipo de publicación, el público y la intencionalidad del editor en relación con el hecho sobre el que se informa (Van Dijk, 1998). La visión del mundo de cada periódico, dentro de su respectiva comunidad inmigrante, es única. Su versión de la realidad, de $s u$ realidad en el universo americano, ofrece una perspectiva singular que puede ayudar a comprender dinámicas sociales ajenas a la cultura local dominante (Rhodes, 2010, p. 49) o también mostrar el nivel de influencia pública en su contexto político y socio-económico (Madison, 1976).

\section{UN MEDIO DE SUPERVIVENCIA Y UN RECURSO COMUNI- TARIO ESENCIAL}

Para muchos inmigrantes, los periódicos se convirtieron en un nexo de unión fundamental entre su comunidad, su país de origen y los Estados Unidos. Una de las primeras funciones de la prensa étnica fue educar a los inmigrantes en sus diferentes roles como ciudadanos americanos, proporcionarles información sobre sus países de procedencia y promover incluso causas políticas. Sus cometidos se fueron adaptando a las necesidades de las poblaciones a medida que iban cambiando, por ejemplo, su relación con el uso del inglés. Cuando los inmigrantes creaban nuevas familias en Norteamérica, con descendientes escolarizados en inglés, el incremento de lectores en la lengua local hizo que muchos periódicos étnicos ofreciesen también contenidos en las dos lenguas.

Desde sus orígenes, la prensa étnica ha tratado de hallar un nicho de mercado complementario al de la prensa local americana, publicando noticias que aquella no ofrece, particularmente las relacionadas con los países de origen de los inmigrantes, sobre políticas de inmigración o de nacionalización, acerca de los acontecimientos públicos dentro de la colonia, entre otras (Rhodes, 2010, pp. 54-55). Algunos eran portavoces de instituciones corporativas o religiosas. La prensa étnica era un medio de supervivencia, pero también una oportunidad para crecer profesionalmente. Además de ofrecer datos e informaciones interensantes para la vida como inmigrante, estimulaban la identificación cultural y espiritual necesaria para integrarse en un entorno nuevo y desconocido. Tal y como manifestaba en un editorial el semanario 
neoyorquino $A$ Luta, la prensa podía ser un instrumento vital para la supervivenvia de la comunidad, su propia "alma":

"A imprensa portuguesa é a alma da colónia! É ela que anuncia as nossas festas, defende os interesses dos nosso compatriotas, faz propaganda das colectividades, publica noticias da nossa Pátria, aviva o patriotismo, ventila questões locais e leva a travez dos nucleos portugueses as noticias tristes dos que exalaram neste pais o último sopro de vida, longe da nossa terra que lhes serviu de berço (...)" (A Luta, $\mathrm{n}^{\circ} 10$ (año 2), 2 de febrero de 1938, p. 1).

De acuerdo con R. E. Park (1922), la mayoría de los periódicos eran fundados por personas que tenían los recursos suficientes, relacionados en ocasiones con entidades bancarias o agentes de pasaje, como fue el caso de Guilherme Machado Luiz, propietario del diario Alvorada, fundado en 1919, que se transformó en 1927 en el Diario de Noticias. Hubo otros que contaron con el apoyo de entidades asociativas, fraternales, políticas o religiosas para afrontar el proyecto editorial con éxito. Por esta razón, algunos periódicos surgieron financiados por congregaciones religiosas o por sacerdotes que asumían un protagonismo que iba más allá de sus funciones propiamente espirituales (Machado, 2012; Liptack, 1989; Baumgarter, 1931). En el caso de la comunidad luso-americana, de hecho, hubo varios sacerdotes ejercieron de editores de varias publicaciones, con línea editorial propia y orientación política. Entre ellos, el más destacado fue el padre Joseph (José) Cacella, que fundó y dirigió A Luta (Nueva York) desde 1936 hasta la década de los setenta.

El negocio de la prensa étnica, especialmente si no era en inglés, dependía mucho de la audiencia de la propia comunidad. Encontrar los lectores era fácil en las áreas urbanas, cuando los inmigrantes se concentraban en pequeñas ciudades. Pero si la colonia se dispersaba o no era muy numerosa, los costes de promoción y distribución aumentaban demasiado. Por esta razón, muchas publicaciones periódicas eran fugaces o tenían una periodicidad irregular. Así lo constata el Cónsul General de Portugal en Nueva York, Victor Verdades de Faria, a su embajador en Washington en un informe sobre la prensa luso-americana el 20 de agosto de 1935:

“(...) Quanto a Imprensa, Nova York tem visto aparecer e desaparecer varios semanários, pelo menos cinco em sete anos, nunca tendo obtido nenhum o desafogo económico para poder subsistir. Todos os diretores têm sido indivíduos de muito boa vontade, mas sem a complexa preparação técnica que o cargo exige, lamentando o Cónsul Geral o seu fracasso, já pela falta que, a pesar de tudo, uma folha redigida em português faz na sua circunscrição (...) O último semanário existente no distrito Consular 'A Tribuna' suspendeu há pouco a sua publicação por dificuldades financeiras." (Arquivo Histórico Diplomático de Lisboa. Embajada de Portugal en Washington. Caja $\mathrm{n}^{\circ}$ 36, carpeta "Relações com a colónia portuguesa, 1933-1936"). 
Por otra parte, el analfabetismo de muchos inmigrantes llegados en las primeras oleadas complicaba aún más la búsqueda y fidelización de los lectores que podrían hacer sostenible cada nueva edición. Sin embargo, los editores asumieron una función educadora, especialmente para informar a los inmigrantes sobre aquellos aspectos relacionados con la convivencia en el entorno local (Rhodes, 2010: 127).

\section{LA SIGNIFICACIÓN DE LOS PERIÓDICOS LUSO-AMERICA- NOS: LENGUA Y PERIODISMO}

La comunidad luso-americana no ha sido ajena al fenómeno de la prensa étnica, especialmente en las etapas con mayores flujos migratorios. De acuerdo con los datos del repositorio de periódicos que se han podido catalogar para desarrollar este estudio, los inmigrantes portugueses editaron al menos 167 títulos hasta en 10 Estados diferentes, siendo Massachusetts, con 68, y Califonia, con 49, los que más periódicos en portugués han publicado a lo largo de la historia. La primera publicación periódica en portugués editada en Estados Unidos de la que se tiene conocimiento es el semanario $O$ Jornal de Notícias, que fue fundado en 1877 en Erie (Penn.). $O$ Jornal de Notícias, que se publicó hasta 1884, fue el primer periódico de una serie de periódicos portugueses que surgieron a lo largo del territorio norteamericano en el último cuarto del siglo XIX, localizadas en los lugares donde se fueron estableciendo diferentes núcleos de población de inmigrantes portugueses.

Quizás lo más característico de la prensa luso-americana se refleje en los siguientes aspectos: 1) Es una prensa creada, salvo algunas excepciones protagonizadas por ciudadanos brasileiros y caboverdeanos, por inmigrantes de origen portugués. 2) La gran mayoría de sus fundadores y editores proceden del el archipiélago de Azores. 3) Además de un interés especial por las informaciones relativas a los asuntos azorianos, debido a su vinculación a un país con un extenso imperio colonial es un tipo de prensa con intereses y preocupaciones universales, con noticias relacionadas con África, Asia, América, Oceanía y, por supuesto, Europa. 4) La concentración migratoria en Massachusetts y California la convierten en una prensa que tiene una marca territorial muy particular, con una interesante influencia en las dos costas americanas. Los dos periódicos más relevantes, tanto por su duración como por su calidad e influencia, son el Diario de Noticias, editado en en New Bedford (Mass.) entre 1927-1973, y el semanario Jornal Português, publicado en Oakland (Cal.) entre 1932 y 1997.

El caso del Diario de Noticias es el más paradigmático. Si se tienen en cuenta los años de edición de su predecesor, el Alvorada, que dejó de editarse cuando se inició el Diario de Noticias, su publicación se extiende durante más medio siglo, entre 1919 y 1973. Ambos títulos fueron fundados por el empresario procedente de la isla Terceira (Azores) Guilherme Machado Luiz, que llegó de joven a EE.UU sin saber leer ni escribir. El Diario de Noticias publicó abundantes y variados contenidos sobre 
la comunidad luso-americana, casi sin interrupciones en su edición, ${ }^{5}$ con una clara y manifiesta defensa del idioma y los signos identitarios y culturales de Portugal. Este fue el compromiso fraterno con su audiencia, que transformó en bandera durante su prolongada existencia. En 1966, cuando se resistía a desaparecer en su lucha por sobrevivir, apeló al sentido patriótico de los portugueses publicando anuncios con el siguiente mensaje: "Se é português e sente a necessidade de que o 'Diario de Noticias' viva, indique-nos novos assinantes".

El tema del uso de la lengua vernácula por parte de los inmigrantes es muy complejo, pues habría que analizarlo no sólo desde la perspectiva que contrapone el inglés al portugués, sino también teniendo en cuenta las variantes dialectales existentes entre algunos inmigrantes azorianos y continentales, así como la utilización de anglicismos entre ellos de manera frecuente como resultado de su adaptación a un nuevo contexto idiomático (Pap, 1949). La lectura de la prensa luso-americana, de hecho, muestra que su lenguaje está plagado de calcos lingüísticos y neologismos provenientes del inglés, pero también de incorreciones gramaticales, particularmente en la fase de la primera llegada masiva, en la que la formación de los editores y redactores era más limitada.

A veces, los errores eran atribuídos a problemas técnicos relacionados con la impresión tipográfica. En 1915, O Lavrador Português pide disculpas a sus lectores porque la tipografía americana que utilizaban para imprimir el periódico no disponía de la "ç" ( $\mathrm{n}^{\mathrm{o}}$ 118, año III, 4 de septiembre de 1915, p. 1). Este fue un problema que afectó particularmente al Jornal Português de Oakland, impreso en una tipografía inglesa. Algunas noticias vieron alterado su sentido cuando aparecían ciertas palabras sin la letra cedilla original, como cuando el semanario californiano informa que Alemania cedía a Portugal algunos aviones de "caca" (Dias, 2009, p. 74). La falta de recursos humanos profesionales también fue la causa de errores de tono incluso burlesco. En 1940, el Jornal Português publicó un anuncio de la cooperativa de avicultores Poultry Producers of Central California en la que explica que la sociedad " (...) vende os ovos dos seus membros a fim de trazer para êles o valor pleno do mercado (...)" (Jornal Português. "Número Conmemorativo dos Centenários de Portugal, 1140-1940”, s/n). Sin embargo, más allá de los errores tipográficos, el periódico de New Bedford (Mass.) A Era Nova publicó el 12 de enero de 1924 un editorial en el que criticaba abiertamente el lenguaje que utilizaban los periódicos de la colonia:

“(...) Se a imprensa portuguesa da América do Norte houvesse de ser o único e exclusivo padrão por onde aquilatar o valor da Colónia, seriamos obrigados a confessar, con dolorosa sinceridade, ser ela a mais decadente e atrasada entre todas as que contribuem para a

5 Tan sólo en el tramo final de su existencia, dejó de publicarse algunos días, concretamente los sábados y domingos entre el 27 de noviembre de 1971 y el 19 de octubre de 1973. 
grandeza e progresso dêste poderoso povo. Com tão raras como louváveis excepções, os jornais portugueses são feitos de retalhos mal traduzidos e péssimamente cerzidos, numa linguagem que logo se vê ter sido escrita por mãos que a Providência mais fadara para apontar brochas e pôr tombas do que para manejar uma pena. A bela linguagem de Camões e de Vieira sofre tratos de pôle nesses calvários, onde ela nos aparece mais repugnantemente afistulada do que o Leproso de Aosta." (Carvalho, 1931, p. 131). ${ }^{6}$

En su libro A Lingua Portuguesa nos Estados Unidos, el cónsul Eduardo de Carvalho afirma que la sistemática modificación de las palabras y el uso frecuente de americanismos en el portugués hablado y escrito de los inmigrantes podría considerarse un dialecto. Según él, esta variante dialectal se manifiesta a través de cuatro rasgos principales: "termos ingleses e americanismos, aplicados a coisas e objectos que o imigrante desconhecia em Portugal; termos portugueses empregados numa acepção diferente; frases inglesas e modismos americanos traduzidos à letra para português; uso da sintaxe inglesa" (Carvalho, 1925, p. 67). Carvalho atribuye una función primordial a la prensa en la difusión y forja de esta "neolengua" creada por la comunidad luso-americana. La falta de preparación y de pericia profesional de los editores para traducir informaciones del inglés o para escribrir correctamente en portugués, es una de las principales causas en el uso del nuevo vocabulario, según el diplomático luso. Del catálogo de ejemplos que publica Carvalho, extraemos los siguientes casos: "Bavaria" por Baviera; "cometer suicidio" por suicidar-se; "Escola Alta" por High School; "operar" por guiar (conducir); "polono" por polaco; "Remoto Oriente" por Extremo Oriente; "Arames-verdes" por Adamsville; "Betefete" por New Bedford; "Canéric"a o "Canériquete" por Connecticut; "Mãe-e-filha" por Mansfield; "Roda-além" por Rhode Island; "Tantín" por Taunton; "Aí dou nou" (non sé), por I don't know; "dar um pári” (organizar una fiesta), por to give a party; "não se boda" (no se incomode), por don't bother; "aconte por account; "andateca" (agente de funerales), por undertaker (Carvalho, 1925, pp. 68-81). Por otra parte, algunos inmigrantes portugueses, en su deseo por favorecer su rápida integración $\mathrm{y}$, probablamente, por evitar su estigmatización, adaptaban sus propios nombres y apellidos al inglés: John por João, Mary por Maria, Tony por António, Perry por Pereira, etc. Asunto que tuvo repercusión en algunos periódicos en portugués, pues parece ser que este fenómeno era mayor que en las colonias de otras etnias. El Diario de Noticias lo veía como una falta de sensibilidad con los valores de la cultura portuguesa $\left(\mathrm{n}^{\mathrm{o}} 2648,16\right.$ de enero de 1928, p. 2). Consciente de los problemas por los que atravesaba la lengua portuguesa en Estados Unidos, A Alvorada argumentaba en un editorial del 6 de diciembre de 1926, que sólo había dos medios para conservar el idioma portugués: los periódicos y las iglesias:

6 El libro, basado en un informe de carácter oficial para el gobierno de Portugal es un documento valioso en el que se puden encontrar, entre otros contenidos, la relación completa de la bibliografía sobre cultura portuguesa existente en los centros de enseñanza superior y bibliotecas principales de Estados Unidos. 
“(...) Porque não devemos esquecer, uma parte também importante no afervoramento desse culto cabe ineludivelmente aos nossoas sacerdotes. Se não fosse o jornal e o púlpito quase teria desaparecido o uso da lingua portuguesa em territorio americano. E todavia torna-se necessario, para que o mal não alastre mais ainda, que todos reforcem a propaganda, que todos ponham neste assunto o seu maior interesse e empenho (...)" (A Alvorada, 6 de diciembre de 1926, p. 2).

En relación con la defensa del idioma y los valores culturales lusos en Norteamérica, los editoriales de muchos periódicos portugueses apelaban, con frecuencia, a una retórica nacionalista, patriótica o etnocéntrica aderezada, a veces, de una cierta melancolía. El fiel compromiso con la lengua y sus tradiciones culturales de este tipo de prensa, representaban para la popular poetisa Josefina do Canto e Castro, un «abraço fraternal» para educar emocionalmente a los inmigrantes. Los trabajadores de periódicos como el Diario de Noticias eran, para ella, «um punhado de poetas» que escribían diariamente «o mais belo poema de amor á Pátria Portuguesa nos Estados Unidos». (Diario de Noticias. Número Especial del 50 Aniversario, 12 de mayo de 1969, s. p.). Una impresión que fue compartida por el periodista y poeta Joaquim de Oliveira, que publicó un artículo lírico titulado «Salvé Diario de Noticias de New Bedford» (Diario de Noticias, 31/12/1935, p. 2.). Este argumento nacionalista era un mensaje recurrente en los editoriales de la prensa lusófona, especialmente en el Diario Noticias, que asumió una función de defensor e instructor de la cultura y la lengua portuguesa en Estados Unidos, tal y como expresó su director, João R. Rocha, en un artículo publicado el 20 de enero de 1930 $\left(n^{\circ}\right.$ 928, 20/01/1928, p. 1).

\section{MARCAS DEL IMAGINARIO NARRATIVO LUSO-AMERICANO}

Los periódicos luso-americanos han tenido un importante rol no sólo como instrumentos de cohesión social entre los inmigrantes y como puentes de conexión emocional con sus lugares de origen, sino también como instrumentos pedagógicos para crear espacios de intersección cultural histórica entre los valores de su propia idisioncrasia y los signos culturales de la sociedad americana o de otras comunidades de inmigrantes allí establecidas. Con el tiempo, desarrollaron una narrativa mitológica sobre aquellos aspectos más sobresalientes de la presencia portuguesa en territorio norteamericano que han contribuído a crear un imaginario propio entre los ciudadanos de origen portugués. En el discurso periodístico de este tipo de prensa se ha venido consolidando un relato historicista y etnocéntrico que resalta y reafirma las huellas de la presencia lusófona remontándose a momentos épicos del pasado de gran relevancia simbólica para los inmigrantes luso-americanos. Esta narrativa etnocéntrica reivindica las huellas lusófonas en los orígenes de Estados Unidos a través, esencialmente, de tres hitos que funcionan como mitos fundacionales de la presencia lusa en América del Norte: el descubrimiento de la Costa Este por 
Rodrigues Cabrilho, la supuesta vinculación a Portugal de la piedra de Dighton y la contribición a la independencia americana de Peter Francisco.

Es un hecho que la presencia portuguesa en América del Norte no se inicia con los primeros flujos migratorios en el siglo XVII, sino que es anterior, pero siempre en el marco de un relato simbólico que ancla la llegada de los primeros portugueses a la época de los descubrimientos, como hace Cardozo (1976). Sin embargo, este es el argumento predominante de una narrativa común en la prensa luso-americana que reivindica las raíces culturales lusófonas de Norteamérica mediante la mitificación de determinados acontecimientos históricos con participación portuguesa, que ha hecho emerger un sentimiento de orgullo étnico. Según este discurso, la llegada de portugueses se remontaría simbólicamente a la colonización española, cuando soldados y marineros de origen luso participaron en las expediciones al servicio de España desde sus territorios coloniales en Centroamérica y el Caribe. Entre todos ellos, hubo uno que destacó especialmente. Fue el marino João Rodrigues Cabrilho (conocido en la literatura histórica española como Juan Rodríguez Cabrillo), que se convirtió en el primer navegante en alcanzar la costa de California, a donde llegó el 28 de septiembre de 1542 en una expedición marítima procedente de México (Dias, 2009: 9-10). Este episodio es particularmente importante porque se convirtió en uno de los momentos épicos a los que de forma recurrente los inmigrantes lusoamericanos a través de sus periódicos han apelado para valorizar la contribución portuguesa a la conquista del territorio norteamericano y la posterior fundación de los Estados Unidos de América. Como expresión paradigmática de esta visión etnocéntrica, en California se fundó en los años treinta una extensa red de clubes sociales en varias ciudades a los que se asociaron varios miles de inmigrantes que editaban una revista titulada Cabrillo Commentator. Discoverer of California, que era una publicación destinada a reivindicar el origen luso del descubrimiento de California. Incluso los dos periódicos más influyentes y longevos de la prensa luso-californiana, el Jornal Português y A União Portuguesa, publicaron en 1942 sendos extensos números conmemorativos dedicados al cuarto centenario del descubrimiento portugués de California (Jornal Português, $\mathrm{n}^{0} 518,3$ de julio de 1942, p. 37; A União Portuguesa, 1887-1937. Número conmemorativo del 50 aniversario, 28 de marzo de 1937). Para comprender la gran significación que para los luso-californianos tenía este hecho histórico, Joaquim Rodrigues da Silva Leite, exeditor de Portugália, de Cabrilho Comentator y de A Revista Portuguêsa, resumió en términos raciales el espíritu de los inmigrantes sobre este hito del pasado: “(...) dificilmente se encontrará na História outro nome que em si contenha tantas afirmações das mais belas qualidades da raça lusa" ( A União Portuguesa, 28 de marzo de 1937, p. 23).

Otro de los episodios que la narrativa periodística luso-americana ha incorporado a su discurso legitimador de la presencia lusitana en los albores de la exploración y conquista de América es la constancia histórica de que otro navegante portugués de origen azoriano, Miguel Corte Real, exploró la región de Labrador y 
Terranova en los inicios del siglo XVI, aunque no hay datos exactos sobre si llegó o no a desembarcar en el actual territorio de Estados Unidos, pues se cree que su barco naufragó en algún punto desconocido de la Costa Este de Norteamérica. Sin embargo, el descubrimiento de la Piedra de Dighton en Berkeley (Massachusetts), en la que el investigador de la prestigiosa Universidad de Brown Edmund Delabarre creyó haber hallado inscripciones relacionadas con el explorador portugués, una de las cuales fue descrita como la fecha de 1511, propició un prolongado y controvertido debate que tuvo gran repercusión en los medios de comunicación luso-americanos ("Está gravado na pedra de Dighton o nome dum navegador portuguez?". A Alvorada, n' 2239, 3 de septiembre de 1926, p. 3). Pues de ser ciertas la conclusiones de Delabarre, se probaría que también la Costa Este estadounidense tuvo un descubridor portugués. ${ }^{7}$ Con sus informaciones y artículos sobre el asunto, la prensa étnica portuguesa elevó el interés por la historia de los portugueses en Estados Unidos y contribuyó incluso a desarrollar un cierto sentimiento de patriotismo luso-americano, que promovió la fundación y promoción del museo que el Estado de Massachusetts inauguró para albergar la piedra de Dighton, de la que se guarda un réplica en el Museo da Marinha de Lisboa.

Existe un tercer argumento de legitimación étnica que forma parte del imaginario luso-americano sobre la colonización del territorio norteamericano, que sus periódicos comunitarios contribuyeron a forjar como referentes fundamentales de la identidad portuguesa en Estados Unidos. Entre todos los relatos sobre los colonos de origen portugués que fueron protagonistas en algún momento de la historia americana, los periódicos luso-americanos prestaron una atención especial a la vida de Peter Francisco, que fue un heroico soldado de la guerra de independencia bautizado como "the giant of the revolution" por la literatura histórica norteamericana. Aunque no está verificado de forma fidedigna, se cree que Peter Francisco nació en la isla de Terceira (Azores). Con tan sólo 5 años, fue abandonado (o olvidado, no se sabe bien) el 23 de junio de 1760 por el capitán de un navío portugués en el muelle de City Point (Virginia), donde hizo escala varios días, antes de dirigirse a Brasil. El niño fue adoptado por el juez de la localidad, que averiguó su procedencia y su nombre, que al parecer era Pedro Francisco. Intentó contactar por carta con sus posibles familiares, pero nunca obtuvo respuesta. Cuando Peter Francisco (como pasó a llamarle su nueva familia) creció, en 1777 decidió

7 El profesor de la Brown University Edmund Delabarre creyó encontrar, tras una inspección realizada a la piedra en 1918, la inscripción " 1511 ” y formas que podrían asociarse a cruces y al escudo de Portugal. El hallazgo estimuló el movimiento nacionalista portugués tanto dentro como fuera de la colonia, hasta el punto de que el profesor americano fue condecorado en 1926 por el gobierno del Estado Novo. Sin embargo, la teoría de Delabarre no fue avalada por los estudios científicos posteriores. Aún así, el médico, investigador aficionado y colaborador de la prensa luso-americana Manuel Luciano da Silva, decidió hacer una intensa campaña a favor de la teoría de Delabarre, que tuvo una gran repercusión mediática. Sobre la teoría de Delabarre, véase, por ejemplo el artículo de Mazzaneta, Louis O. "New England's Little Portugal”, publicado en National Geographic, enero de 1975, p. 98. 
alistarse en el ejército independentista. En la guerra contra Gran Bretaña, demostró un gran coraje y valentía, que le valieron el reconocimiento público de George Washington, que elogió su gran heroísmo: "Without him, we would have lost two crucial battles, perhaps the war, and with it our freedom". ${ }^{8}$ La historiografia popular lo ha convertido en uno de los personajes militares de la revolución norteamericana más venerados. Existe incluso una Society of Descendents of Peter Francisco, que ha logrado construir el árbol genealógico completo de sus descendientes. ${ }^{9}$

A pesar de haber sido obviado en muchos de los relatos oficiales de la historia de la nación americana, la prensa étnica lusa siempre ha reivindicado su contribución al nacimiento de Estados Unidos (Jornal Português dedicado "Aos portugueses na Guerra de Independencia americana". No 939, 22 de septiembre de 1950, p, 19). De hecho, se han promovido acciones de Relaciones Públicas para reconocer su figura. En 1926, el gran periodista portugués establecido en Fall River (Mass.) Vasco de Sousa Jardim, que sería director y propietario del Luso-Americano de Newark, junto al padre Augusto Furtado, de Somerset (Mass.), organizaron una campaña para dar a conocer el origen portugués de Peter Francisco entre los inmigrantes lusos ("Capítulo 21". Luso-Americano, 18 de noviembre de 1989, p. 33), con el apoyo de la revista American Legion y la União Portuguesa Continental de Boston, que creó la "Medalha Peter Francisco" para distinguir a aquellas personas que hubieran destacado en la promoción de Portugal y la cultura portuguesa. Entre los condecorados con esta distinción, están John F. Kennedy (presidente de Estados Unidos), Basil Brewer (propietario del Standard Times, de New Bedford), Joe Martin (portavoz de la Casa Blanca con los presidentes Harry Truman y Dwight D. Eisenhower), John dos Passos (escritor de ascendencia portuguesa), João R. Rocha (director y propietario del Diario de Noticias) y Anibal Branco (editor de $O$ Independente). En Newark, el periódico Luso-Americano y la Portuguese-American Scholarship Foundation consiguieron también que el triángulo urbano entre la Ferry Street, el Edison Place y la Railroad Avenue, en la que residían muchos portugueses, fuese bautizado con el nombre de Peter Francisco Park, que todavía hoy existe en la capital de New Jersey. La obra fue culminada en 1976 con la inauguración de un obelisco en honor al héroe luso-americano en la plaza homónima (ibídem). Además, el gobernador del Estado de Massachusetts Christian A. Herter, designaría la jornada del 15 de marzo como Peter Francisco's Day desde 1953 y el alcalde de New Bedford, Arthur R. Harriman, hizo pública el 12 de marzo de 1954 una proclamación oficial publicada en la prensa portuguesa para que la bandera de Portugal fuese hasteada junto a la enseña americana en el edificio del ayuntamiento, en honor a a Peter Francisco y a la comunidad lusoamericana (Diario de Noticias, $\mathrm{n}^{\circ}$ 10.640, 12 de marzo de 1954, p. 2).

8 Disponible en: http://www.peterfrancisco.org/aboutpeter.php

9 Véase el portal web: http://www.peterfrancisco.org/ 


\section{CONSIDERACIONES FINALES}

Al igual que otras comunidades de inmigrantes que se establecieron en Estados Unidos a lo largo de la historia, la prensa étnica portuguesa ha desarrollado una narrativa y un modelo de representación de la realidad relacionado con la idiosincrasia de sus valores culturales y su rol dentro de la sociedad de acogida, empleando un imaginario simbólico y una estructura discursiva que utiliza códigos de interpretación etnocéntricos para justificar su presencia en Estados Unidos. Dentro de una dinámica socio-cultural, las consecuencias fundamentales de este tipo de publicaciones periódicas van desde mantener vivos sus lazos emocionales con los lugares de origen o afirmar y reforzar sus vínculos culturales, creando en sentimiento de comunidad a través del uso de la lengua portuguesa, hasta el desarrollo de un servicio comunicativo esencial para informar sobre las actividades de la colonia, ayudando así a integrar y a defender los intereses de los inmigrantes.

Dos de los casos históricos más paradigmáticos de este tipo de prensa son el Diario de Noticias de New Bedford (Mass.) y el Jornal Português de Oakland (Cal.), en los que se ha forjado una retórica periodística que reivindica los orígenes lusos de Estados Unidos, tanto desde un visión territorial o cultural como desde una perspectiva nacional. Su narrativa ha legitimado la presencia lusa en Norteamérica y ha servido al tiempo para reafirmar no sólo un cierto orgullo patriótico que vincula a los inmigrantes con un país de pasado imperial cuya lengua y signos culturales comparten, sino también para estimular la identificación con los valores nacionales de la sociedad estadounidense, de cuya historia se sienten actores participantes a través de hechos, hitos o figuras históricas relevantes, como la del héroe de la independencia americana Peter Francisco, que el discurso propagandístico de la prensa luso-americana ha convertido en referentes culturales o mitos fundacionales sobre el origen de Estados Unidos. A través de la identificación con estas huellas y marcas históricas de carácter etnocéntrico portugués se ha producido una especie de galvanización de la identidad lusófona dentro de la sociedad estadounidense que ha contribuído a forjar un nuevo ideario para los inmigrantes de origen lusófono.

\section{REFERENCIAS BIBLIOGRÁFICAS}

Avendaño, Fausto (1982). Portuguese Immigration into the United States. En Cuddy, Dennis Lawrence. Contemporary American Immigration. Interpretative Essays (European). Boston: Twayne Publishers, pp. 155-172.

Baganha, Maria Ioannis (2009). The Lusophone Migratory System: Patterns and Trends. International Migration, n. 47-3, pp. 5-20. DOI: 10.1111/j.1468-2435.2009.00522.x

Barrow, Claude W. (ed.). (2002). Portuguese Americans and Contemporary Civil Culture in Massachusetts. North Dartmouth: Tagus Press, Center for Portuguese Studies and Culture-University of Massachusetts Dartmouth. 
El "alma de la colonia"... - A. Pena Rodríguez y M. È. de Oliveira Lima

Baumgarter, A. W. (1931). Catholic Journalism. A study of its development, 1789-1930. New York. Columbia University Press.

Blanchard, Margaret A. (ed.). (1998). History of the Mass Media in the United States. An Encyclopedia. Chicago-London: Fitzroy Dearborn Publishers.

Cardozo, Manoel da Silveira (1976). The Portuguese in America (590 b.C-1974). New York: Oceana Publications.

Carvalho, Eduardo de (1931). Os Portugueses da Nova Inglaterra. Rio de Janeiro: A Leitura Colonial.

Carvalho, Eduardo de (1925). A Língua Portuguesa nos Estados Unidos (extracto do relatório de Boston, de 9 de abril de 1924). Boston: Editora Emprêsa de Propaganda Patriótica.

Correa, Genevieve. B. \& Knowlton Edgard C. (1982). The Portuguese in Hawaii. En Ethnic Sources in Hawai'i. A Special Issue for The University of Hawai'i’s SeventyFith Year, Honolulu: The United Press of Hawaii, pp. 70-77.

Cullen, Jim (2003). The American dream: A short history of an idea that shaped a nation. Oxford-New York: Oxford University Press.

Dias, Eduardo Mayone (2009). A Presença Portuguesa na California. San Jose (Calif.): Portuguese Heritage Publications.

Felix, John Henry and Senecal, Peter F. (1978). The Portuguese in Hawaii. Honolulu: Centenial Edition.

Gomes, Geoffrey L. (1995). The Portuguese Language Press in California: The Response to American Politics, 1880-1928. Gávea-Brown. A Bilingual Journal of Portuguese American Letters and Studies, n. 15-18, pp. 5-90.

Goulart, Tony (2002). The Holy Ghost Festas. A Historic Perspective of the Portuguese in California. San Jose: Portuguese Heritage Publications of California.

Graves, Alvin Ray (2004). The Portuguese Californians. Immigrants in Agriculture. San Jose, Calif.: Portuguese Heritage Publications of California.

Holton, Kimberly D. \& Klimt, Andrea (eds.). (2009). Community, Culture and the Makings of Identity. Portuguese-Americans along Eastern Seabord. North Dartmouth: Tagus Press, Center for Portuguese Studies and Culture-University of Massachusetts Dartmouth.

Ireland, Sandra L. Jones (1990). Ethnic Periodicals in Contemporary America: an Annotated Guide. New York: Greenwood Press.

Knowlton, Edgard C. (1960). The Portuguese Language Press in Hawaii. Social Process in Hawaii, n. 24, pp. 89-99.

Liptack, Dolores A. (1989). Immigrants and Their Church. Makers of the Catholic Community. New York-London: McMillan.

Luca de Tena, Gustavo (1993). Noticias de América. Vigo: Nigra. 
Machado, Joe, et al. (2012). Power of the Spirit. A Portuguese journey of building faith and churches in California. San Jose: Portuguese Heritage Publications of California.

Madison, Charles A. (1976). Jewish publishing in America. The impact of Jewish writing on American culture. New York: Sanhedrin Press.

McDonald, Jason (2007). American Ethnic History. Themes and Perspectives. News Brunswick (New Jersey): Rutgers University Press, 2007.

Miller, Sally M. (ed.) (1987). The Ethnic Press in the United States. A Historical Analysis and Handbook. New York-West Port-Connecticut-London: Greenwood Press.

Nasaw, David (2001). The Chief. The Life of William Randolf Hearst. New York: First Mariner Book.

Pap, Leo (1981). The Portuguese-Americans. Boston: Twayne Publishers.

Pap, Leo (1949). Portuguese-American Speech. New York: King's Crown Press (Columbia University).

Park, Robert E. (1922). The Immigrant Press and its Control. New York: Harper \& Brothers.

Pena Rodríguez, Alberto et al. (coord.) (2015). Emigración e exilio nos Estados Unidos. Experiencias de Galicia e Azores. Santiago de Compostela: Consello da Cultura Galega.

Pena Rodríguez, Alberto (2017). Los inicios de la prensa portuguesa en los Estados Unidos de América. Revista Famecos. Mídia, Cultura e Tecnologia, n. 24-2. DOI: 10.15448/1980-3729.2017.2.25558.

Rhodes, Leara (2010). The Ethnic Press: Shaping the American dream. New York: Peter Lang.

Rocha, Gilberta (1991). Dinâmica Populacional dos Açores no Século XX: Unidade. Permanência. Diversidade. Ponta Delgada: Universidade dos Açores.

Strone, P. A. (1988). Portuguese in Hawai. A bibliography. Honolulu: Hawaii State Public Library.

Vaz, Auguat Mark (1965). The Portuguese in California. San Francisco: IDES Supreme Council.

Van Dijk, Teu A. (1998). Ideology. A multi-disciplonary approach. London: Sage Publications.

Vicente, Antonio L. (1998). Os Portugueses nos Estados Unidos de América. Política de Comunidades e Comunidade Política. Lisboa: Fundação Luso-Americana

Williams, Jerry (2007). In Pursuit of Their Dreams. A History of Azorean Immigration to the United States. North Dartmouth: Tagus Press, Center for Portuguese Studies and Culture-University of Massachusetts Dartmouth. 
El "alma de la colonia"... - A. Pena Rodríguez y M. È. de Oliveira Lima

Wittke, Carl F. (1957). The German Language Press in America. Lexington: University of Kentucky Press.

Whorf, Benjamin (1956). Language, Thought and Reality. MIT Press: Cambridge (Mass.).

Zelph, W. P. \& Hough, G. A. 1889. New Bedford, Massachusetts: its History, Institutions and Attractions. New Bedford.

Zubrzycki, Joseph (1958). The role of the foreign-language press in migrant integration. Population Studies, n. 12-1, pp. 73-82. 